Ethos (Jurnal Penelitian dan Pengabdian Masyarakat): 1-7

\title{
Good Mining Practice Sebagai Penopang Pengelolaan Pertambangan BERKELANJUTAN DAN BERWAWASAN LINGKUNGAN
}

\section{GOOD MINING PRACTICE AS THE SUPPORT OF MANAGEMENT OF ENVIRONMENTALLY AND SUSTAINABLE MINING}

\author{
${ }^{1}$ Dudi Nasrudin Usman, ${ }^{2}$ Sri Widayati, ${ }^{3}$ Sriyanti, ${ }^{4}$ Linda Pulungan \\ 1,2,3,4 Fakultas Teknik, Universitas Islam Bandung \\ email : 'dudinasrudinmining@gmail.com; ${ }^{2}$ widayati_teknik@yahoo.com; ${ }^{3}$ sriyanti.tambang@yahoo.com; \\ dan ${ }^{4}$ linda.lindahas@gmail.com
}

\begin{abstract}
Garut Regency is a district that has enough of the potential mineral resources, such metallic minerals and nonmetals including sand and andesite, one of the areas is Mount Guntur. Many factors encourage to stop mining activity, one of them is environmental factors. Therefore, it needs a relocation to other areas, by consideration of the potential mineral deposits, to fulfill the increasing market demand. The relocation is done as a step that mining activities do not interfere with mountain tourism, natural environmental conditions, and policies related to the environment, safety and occupational health and spatial planning. The field observations result, study geological location dominated by Qhg, Qypu, and QYM. The other geological aspects that must be considered is the distribution pattern of the river. The vegetation conditions results show that the types of vegetation found in many locations namely crops and plantations, shrubs and bamboo. Based on the calculation of immeasurable resources, there is Boulder andesite-basalt amounted to 13,515,740 MT, with an estimated average thickness taken from the surface to the deepest point of 60 meters penetration geolistrik, although in fact the thickness of andesite - basalt is absence of definite size, thereby the concretion Factor has a value of $30 \%$.
\end{abstract}

Keywords: Deposition Model, Characteristics Location, Good Mining Practice

\begin{abstract}
Abstrak. Kabupaten Garut merupakan kabupaten yang mempunyai potensi sumber daya bahan tambang berupa bahan galian logam (mineral) maupun non logam diantaranya pasir dan batuan andesit. salah satu wilayahnya di Gunung Guntur. Banyak faktor yang mendorong agar penambangan di wilayah tersebut dihentikan, salah satunya faktor lingkungan. Sehingga perlu relokasi ke wilayah lain yang mempunyai potensi bahan tambang untuk memenuhi permintaan pasar yang semakin meningkat. Relokasi tersebut dilakukan sebagai langkah agar aktivitas penambangan tidak mengganggu wisata pegunungan, kondisi lingkungan alam dan sisi kebijakan yang terkait dengan lingkungan, keselamatan dan kesehatan kerja serta tata ruang. Hasil pengamatan lapangan, secara geologi lokasi kajian didominasi oleh Lava Guntur (Qhg), Endapan Rempah Lepas Gunung Muda Tak Teruraikan (Qypu), dan Batuan Gunungapi Muda (Qym). Hal yang harus diperhatikan dalam aspek geologi salah satunya pola sebaran sungai, di lokasi. Hasil kegiatan lapangan menunjukan bahwa jenis vegetasi yang banyak ditemui di lokasi adalah tanaman pertanian dan perkebunan, semak belukar dan bambu. Berdasarkan hasil perhitungan sumberdaya terkira Boulder andesit-basal sebesar 13,515,740 MT, dengan perkiraan ketebalan rata - rata andesit-basal diambil dari atas permukaan ke titik terdalam dari penetrasi geolistrik 60 meter, walaupun pada faktanya ketebalan andesit - basal tidak ada ukuran pasti, sehingga CF (Concretion Factor) mempunyai nilai $30 \%$.
\end{abstract}

Kata Kunci: Model Endapan, Karakteristik Lokasi, Good Mining Practice 


\section{Pendahuluan}

Konsep pembangunan dan pemanfaatan yang berkelanjutan merupakan konsep yang memadukan aspek sosial budaya, lingkungan hidup dan pembangunan dalam upaya mensejahterakan umat manusia di bumi ini. Dengan kata lain memanfaatkan seefisien mungkin sumberdaya yang ada melalui peningkatan dan konversi nilai tambah dengan mengedepankan nilai lingkungan dan keadilan sosial serta tetap memberikan kesempatan pada generasi mendatang. Konsep ini juga menekankan pentingnya pengelolaan keteknikan, wawasan sosial kemasyarakatan serta pendekatan lingkungan yang terpadu.

Kabupaten Garut, sebagai salah satu kabupaten di Provinsi Jawa Barat dengan bahan galian industri khususnya yang cukup besar, maka sebagai langkah awal untuk mencegah terjadinya kegiatan eksploitasi bahan galian yang lebih menonjolkan dampak negatifnya, harus dilakukan penataan mulai saat ini sehingga hal-hal yang dikhawatirkan terjadi dikemudian hari dapat diminimalisir keterjadian dan dampaknya. Pentingnya aplikasi Good Mining Practice sebagai tujuan meningkatkan kualitas pengelolaan pertambangan yang akan berimplikasi terhadap pengelolaan lingkungan hidup sekitar.

Good Mining Practice adalah suatu kegiatan pertambangan yang mentaati aturan, terencana dengan baik, menerapkan teknologi yang sesuai yang berlandaskan pada efektifitas dan efisiensi, melaksanakan konservasi bahan galian, mengendalikan dan memelihara fungsi lingkungan, menjamin keselamatan kerja, mengakomodir keinginan dan partisipasi masyarakat, menghasilkan nilai tambah, meningkatkan kemampuan dan kesejahteraan masyarakat sekitar serta menciptakan pembangunan yang berlanjutan.

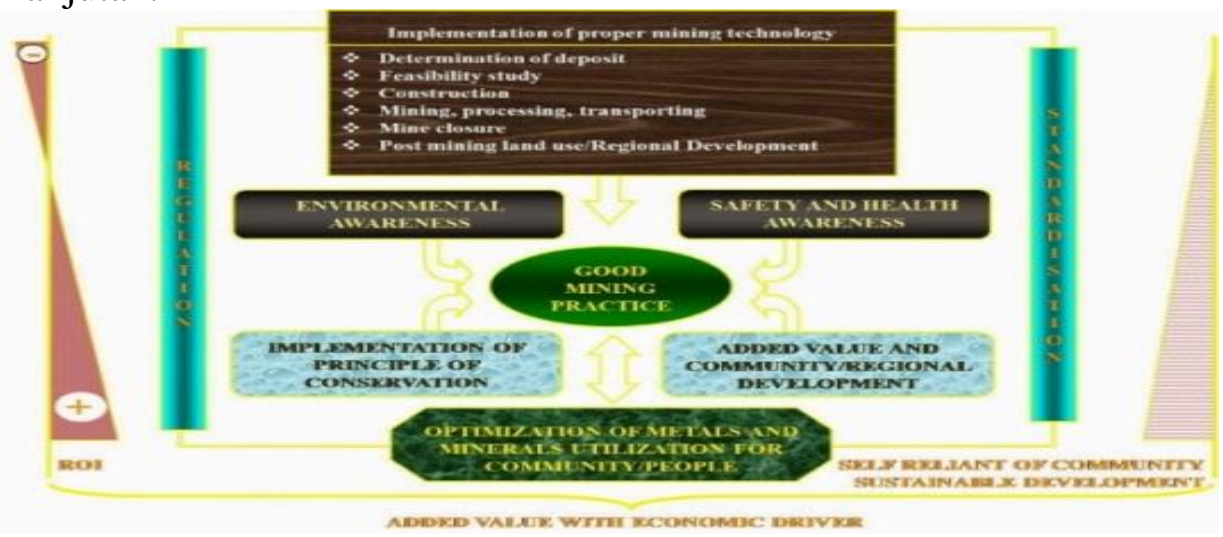

Gambar 1. Paradigma Pengelolaan Pertambangan yang Baik dan Benar (Sumber : Suyartono, 2003)

Berdasarkan UU No. 4 Tahun 2009 tentang Pertambangan Mineral dan Batubara, ada beberapa ciri Good Mining Practice, antara lain:

[1]. Kepedulian terhadap K3 (Kesehatan dan Keselamatan Kerja) serta keselamatan operasi pertambangan;

[2]. Penerapan kaidah lindung lingkungan dengan melakukan pengelolaan dan pemantauan lingkungan pertambangan, termasuk reklamasi serta pascatambang;

[3]. Pengelolaan semua sisa/residu dari kegiatan pertambangan dalam bentuk padat, cair, atau gas sampai memenuhi baku mutu lingkungan sebelum di lepas ke media lingkungan;

[4]. Penerapan prinsip konservasi sumberdaya dan cadangan;

[5]. Menciptakan nilai tambah bagi pengembangan wilayah dan masyarakat sekitar; 
[6]. Kepatuhan terhadap hukum dan perundangan yang berlaku;

[7]. Menggunakan standarisasi keteknikan dan teknologi pertambangan yang tepat dalam aktivitasnya;

[8]. Pengembangan potensi dan kesejahteraan masyarakat setempat terutama dari optimalisasi dan konversi pemanfaatan mineral;

[9]. Menjamin keberlanjutan kegiatan pembangunan setelah periode pascatambang (mine closure);

[10]. Memberikan benefit yang memadai bagi investor.

Dalam mengaplikasikan Good Mining Practice (GMP) maka perlu memperhatikan beberapa hal yang harus diterapkan, sebagai berikut (Suyartono, 2003):

[1]. Eksplorasi dengan presisi tinggi

[2]. Kegiatan eksplorasi untuk mengetahui karakteristik sumberdaya dan cadangan bahan tambang (mineral dan batubara) dan bahan galian industri dilakukan dengan menggunakan teknologi eksplorasi yang ada, untuk memastikan sumberdaya dan cadangan bahan tambang yang tersedia benar-benar dapat dikelola semaksimal mungkin.

[3]. Pemilihan teknologi yang tepat (recovery)

[4]. Teknik pertambangan yang diterapkan harus benar-benar berpedoman pada metode penambangan yang efektif, aman dan berwawasan lingkungan, sesuai kaidah yang berlaku.

[5]. Efisiensi penggunaan lahan

[6]. Melakukan upaya pengendalian erosi dan sedimentasi, dengan: (a) membuat sarana kendali erosi dan sedimentasi sebelum kegiatan pembukaan lahan; (b) membatasi luas dan lamanya lahan terbuka; (c) berupaya untuk menahan sedimen dekat dengan sumbernya; (d) mengalirkan air limpasan menjauh dari daerah yang terganggu; (e) meminimalkan panjang dan kemiringan lereng; (f) stabilisasi daerah terganggu sesegera mungkin; (g) memperlambat kecepatan air limpasan; serta (h) perawatan terhadap sarana kendali erosi secara berkala.

[7]. Pengelolaan tanah pucuk dan batuan penutup, pengendalian erosi dan sedimentasi, serta pengelolaan air asam tambang (AAT)

[8]. Pengelolaan batuan penutup, harus dilakukan dengan: (a) mengisikan kembali batuan penutup ke bekas tambang (backfill/inpit dump); (b) pemilihan lokasi yang stabil serta tidak ada potensi cadangan; (c) mengikuti kaidah teknis kajian stabilitas timbunan; (d) serta pengelolaan material pembangkit asam.

[9]. Penggunaan air kerja, perlindungan sumber-sumber air

[10]. Pengelolaan air kerja serta air limbah pertambangan dalam rangka perlindungan kualitas perairan umum.

[11]. Penambangan tuntas

[12]. Penambangan harus memiliki tingkat perolehan yang tinggi (tambang sampai tuntas, habis/total mining), sehingga tidak banyak yang terbuang sia-sia bahkan tidak tertambang.

[13]. Reklamasi segera

[14]. Melakukan kegiatan reklamasi segera terhadap lahan tambang yang sudah selesai.

[15]. Pemantauan lingkungan

[16]. Melakukan kegiatan pemantauan kualitas lingkungan untuk mengetahui kinerja pengelolaan lingkungan yang telah dilakukan. 


\section{Metode Penelitian}

Metodologi yang akan digunakan dalam penelitian ini adalah kajian yang tentunya fokus utama adalah kajian lokasi penambangan bahan galian pasir dan komponen lain yang terkait dengan keberadaannya dalam kaitannya dengan menyediakan lahan untuk relokasi penambangan pasir, batuan dan sirtu di sekitar Puncak / Punggungan Gunung Guntur.

Selanjutnya data dan informasi dimaksud diolah dan ditabulasi untuk kemudian dilakukan analisa secara deskriptif dan kuantitatif disesuaikan dengan keperluan dan konteks permasalahan yang ditemukan. Beberapa sektor ekonomi yang berpotensi untuk dikembangkan seperti pertanian, perkebunan, perdagangan dan industri merupakan variabel yang digunakan dalam menganalisa permasalahan.

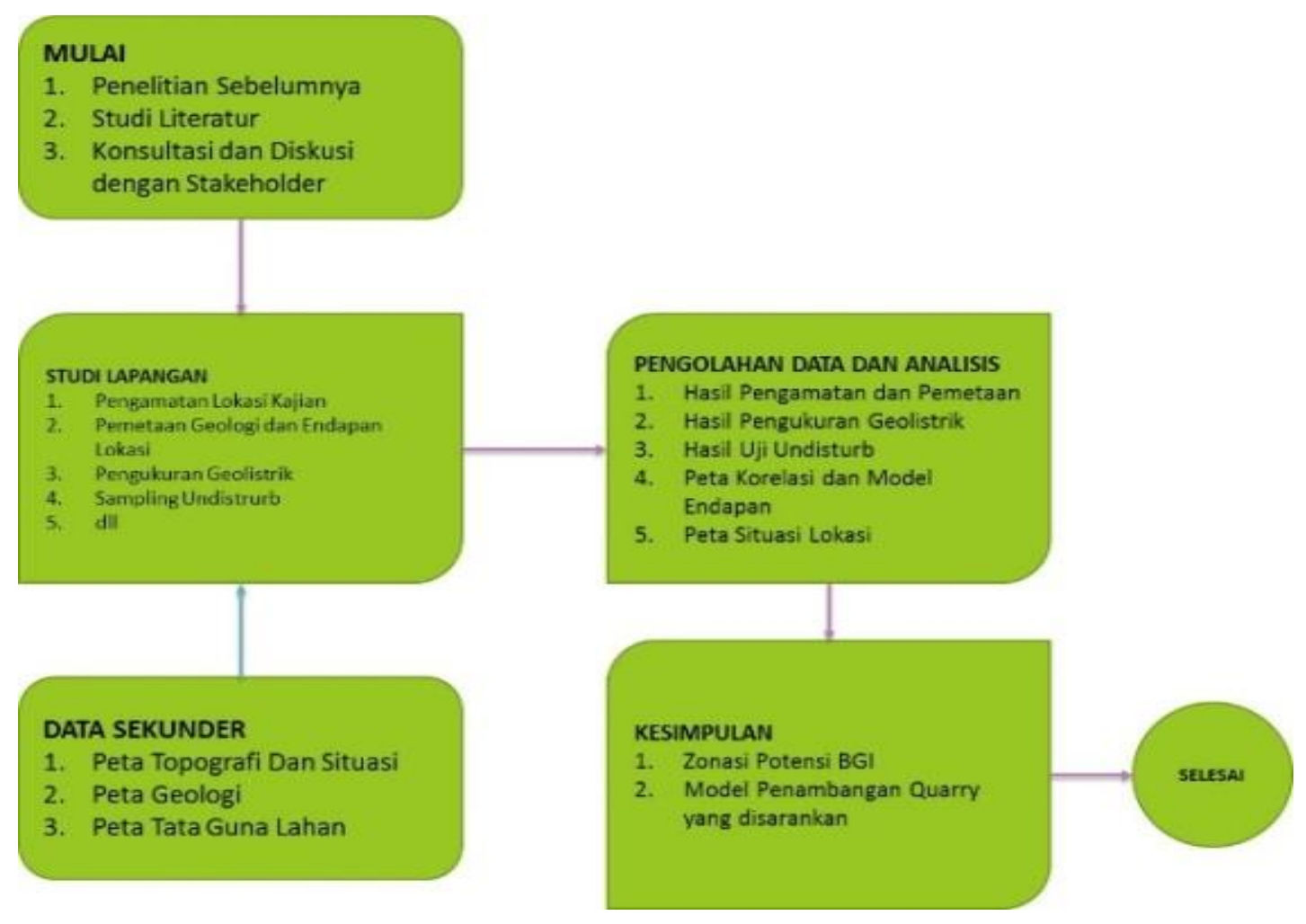

Gambar 2. Metodologi Penelitian

\section{Hasil dan Pembahasan}

Kegiatan lapangan untuk penelitian ini dilakukan dalam beberapa tahapan kegiatan sebelum kegiatan inti yaitu kajian lokasi penambangan berbasis kepada Good Mining Practice yang diperuntukkan bagi relokasi kegiatan penambangan pasir dan batu Eks-gunung Guntur dan sekitarnya.

Lokasi penelitian ini difokuskan untuk wilayah Desa Kandangmukti, Kecamatan Leles, Kabupaten Garut. Lokasi ini secara status kepemilikan yaitu Milik Kabupaten Garut dalam hal ini yaitu Dinas Pertambangan dan Energi. Saat ini kondisi eksisting di sekitar lokasi kajian sudah terdapat aktivitas penambangan baik di akses jalan menuju lokasi maupun lokasi yang bersebelahan dengan lokasi kajian. 
Di lapangan memperlihatkan bahwa kondisi pola aliran sungai dendritic hal ini dapat dilihat pada peta topografi yang menginformasikan mengenai data sebaran sungai. Khusus di wilayah kajian, hanya dilintasi oleh 2 aliran sungai, namun kenyataan di lapangan ada lebih dari 2 anak sungai yang melintasi di wilayah kajian dengan kondisi aliran sungai ada yang selalu mengalirkan air dan ada juga yang intermetent (sungai mengalirkan air dalam kondisi hujan), kondisi keberadaan sungai bukan menjadi sumber utama masyarakat di dalam memenuhi kebutuhan untuk mengelola lahan salah satunya mengairi kebun karena sebagai wilayah masyarakat membuat sumuran sumuran kecil untuk mendapatkan air

Hasil pengamatan di lapangan terhadap pola sebaran sungai di lokasi kajian menunjukkan bahwa dimensi sungai di lokasi kajian baik yang didalam lokasi maupun yang di bagian luar lokasi mempunyai dimensi lebar antara 2 - 5 meter dan kedalaman antara 1,5-3 meter.

Pada sungai 03 (Sungai Cibojonggoweng) terlihat dibagian dasar sungai bongkah-bongkah batuan beku dengan ukuran beragam, selain menunjukkan bahwa sungai sudah mendekati hulu, kondisi tersebut memperlihatkan kehadiran endapan batuan khususnya batuan beku cukup dominan dikarenakan lokasi kajian secara aspek geologi masuk pada wilayah dengan formasi batuan beku dan endapan halus (colluvium).

Kondisi vegetasi di lokasi kajian memperlihatkan cukup beragam, namun didominasi dengan perkebunan rakyat. Kondisi vegetasi perlu untuk diketahui dan dipetakan dari awal untuk mengetahui jenis tanaman dan tumbuhan baik local maupun yang varietas tertentu yang dianggap langka, sehingga pada saat kegiatan reklamasi dilakukan bisa ditanami dengan jenis tanaman yang merupakan jenis tanaman lokal dan memudahkan dalam pelaksanaan kegiatan reklamasi dengan menjaga kehumusan tanah pucuk.

Terkait dengan aspek pertanian di wilayah Kabupaten Garut khususnya di Kecamatan Leles, maka dapat dilihat Jumlah Rumah Tangga Usaha Pertanian Pengguna Lahan pada Laporan RPJMD Tahun 2014 - 2019 Kabupten Garut, dimana di Kecamatan Leles terdapat 7.783 Rumah Tangga, menurun sekitar 3,89\% dibandingkan pada Tahun 2003 sebesar 8.098 Rumah Tangga (Data Sensus Pertanian, 2013). Hal ini menunjukkan bahwa sebagian besar lahan yang dibuka adalah untuk area pertanian, terkait dengan itu luasan yang digunakan Rumah Tangga Usaha Pertanian dengan Luas Bukaan Pertanian 158,12 m2, Lahan Sawah 1.009,55 m², Lahan Bukan Sawah 2.442,6 $\mathrm{m}^{2}$ dan Lahan yang dikuasai seluas 3.620,04 $\mathrm{m}^{2}$. Hal ini penting untuk diketahui terkait dengan adanya rencana peruntukkan kawasan menjadi kawasan pertambangan.

Hasil kegiatan lapangan menunjukan bahwa jenis vegetasi yang banyak ditemui di lokasi kajian yaitu tanaman pertanian dan perkebunan (papaya, pisang, tembakau, tomat, jagung, kayu jati, tomat dan lain-lain), semak belukar dan bambu.

Kegiatan pemetaan geologi dan endapan dilakukan terkait untuk mengetahui keberadaan endapan secara lebih rinci lagi khususnya terkait penyebaran endapan baik pasir ataupun batuannya. Lokasi kajian secara umum merupakan endapan sirtu yaitu endapan pasir dan batuan yang merupakan produk letusan gunung api (Lampiran 2).

Secara kajian aspek geologi, dimana berdasarkan Peta Geologi Lembar Garut dan Pameungpeuk, Jawa, oleh M. Alzwar, Tahun 1992 dengan Skala 1 : 250.000 kondisi geologi menunjukkan sebagai bagian dari Lava Guntur (Qhg), Endapan Rempah Lepas Gunung Muda Tak Teruraikan (Qypu), dan Batuan Gunungapi Muda (Qym).

Hasil kegiatan pemetaan di lapangan menunjukkan, dimana secara umum lokasi kajian memberikan gambaran yang hampir sama yaitu ditemukannya bongkah-bongkah produk volkanik, tidak ditemukan batuan yang menerus. Terselimuti oleh endapan pasir volkanik, sebagian endapan pasir mengandung lempung akibat dari aktivitas pelapukan.

Pada hasil pemetaan diatas menunjukkan ketebalan tanah penutup diperkirakan lebih dari 2 meter sebagai endapan pasir volkanik pada wilayah dengan geomorfologi dataran tinggi 
dengan kemiringan lereng $\pm 9 \%$ dan bagian permukaan ditumbuhi oleh vegetasi semak belukar serta tanaman pertanian.

Karakteristik endapan pasir menunjukkan warna hitam agak keabu-abuan, butiran sedang hingga halus, dengan bentuk butir relatif membulat, porositasnya tinggi dan permeabilitas tinggi, mengandung fragmen volkanik.

Berdasarkan hasil perhitungan sumberdaya terkira Boulder andesit-basal sebesar 13,515,740 MT, dengan perkiraan ketebalan rata - rata andesit-basal diambil dari atas permukaan ke titik terdalam dari penetrasi geolistrik 60 meter, walaupun pada faktanya ketebalan andesit - basal tidak adanya ukuran pasti, sehingga CF (Concretion Factor) mempunyai nilai $30 \%$.

\section{Kesimpulan}

Hasil pengamatan dan evaluasi secara regional mengenai lokasi untuk relokasi kegiatan pertambangan pada prinsipnya berada di kawasan yang bisa dijadikan kawasan pertambangan. Selain itu terdapat beberapa faktor daya dukung untuk menyediakan lokasi baru bagi para penambangan di kawasan Gunung Guntur yaitu antara lain aspek teknis (endapan sirtu, daya dukung secara geomekanika baik dari tanah penutup maupun dari endapan), aspek tata guna lahan, aspek lingkungan dan aspek ekonomi. Hasil pengamatan awal secara permukaan menunjukkan bahwa sebaran endapan meliputi hamper semua lokasi kajian, namun faktor tanah penutup yang membedakan dimana ada endapan yang langsung terlihat dengan dipermukaan dan sebagian lokasi keadaan tanah penutupnya cukup tebal sehingga endapan tidak dapat terlihat, hal ini dapat tergambarkan apabila kegiatan pengukuran resistivity sudah dilakukan. Berdasarkan hasil perhitungan sumberdaya terkira Boulder andesit-basal sebesar 13,515,740 MT, perkiraan ketebalan rata - rata andesit-basal dari permukaan ke titik terdalam dari penetrasi geolistrik 60 meter.

\section{Ucapan Terima Kasih}

\section{Daftar pustaka}

Arif Irwandy, dan Gatut S.Adisumo, 2000, Perencanaan Tambang, Diktat Kuliah, Jurusan Teknik Pertambangan ITB, Bandung.

Djumhani, 1999. "Perancangan Eksplorasi Batubara", Diklat Eksplorasi Pengembangan Tambang Batubara, PPTP.

Dudi Nasrudin Usman, et al. 2008. Peranan Pemerintah Daerah dan Industri Pertambangan Rakyat untuk Peningkatan Kualitas Bahan Tambang dalam Mengantisipasi Kebijakan Ekspor Bahan Mentah. Prosiding Kolokium Pertambangan 2008, p 20 - 30. ISBN : 978 - 979 - 841 - 62 - 6.

Dudi Nasrudin Usman, et al. 2008. Optimalisasi Potensi Sumber Daya Mineral dalam Menunjang Pembangunan Berkelanjutan di Tingkat Daerah. Proceeding Seminar Fakultas Teknik UNISBA Tahun 2008. p 22 - 42 ISBN : 978 - 979 - 15631 - 2 - 3

Dudi Nasrudin Usman, et al, 2009., Pemahaman Dampak Lingkungan dari Aktivitas Industri Pertambangan oleh Masyarakat dan Siswa-Siswi SMU di Kabupaten Bandung Barat. Tidak Dipublikasikan.

Dudi Nasrudin Usman, et al, 2001., Peningkatan Ekonomi Regional dengan Memperdayakan Industri Pertambangan Skala Kecil. Prosiding Kolokium Pertambangan 2001, Puslitbang Tekmira, Departemen Energi dan Sumberdaya Mineral. 
Prodjosumarto, Partanto dan Zaenal, 2000, Tambang Terbuka, Buku Ajar, Jurusan Teknik Pertambangan UNISBA, Bandung.

Prodjosumarto, Partanto. 1993, Pemindahan Tanah Mekanis, Diktat Kuliah, Jurusan Teknik Pertambangan ITB, Bandung.

Rudy Sayoga Gautama, 2007, "Pidato Guru Besar "Tantangan Ke Depan Pertambangan Indonesia", Institut Teknologi Bandung.

Septina Ayu H, et al, 2015, Pengawasan Penerapan GOOD MINING PRACTICE pada Pertambangan Batuan Andesit CV SELO PUTRO WONOGIRI Pra dan Pasca Terbitnya Undang-undang No. 23 Tahun 2014 tentang Pemerintahan Daerah. Privat Law. Vol III No. 2 Juli - Desember 2015.

Suyartono, 2003, "Good Mining Practice" Konsep tentang Pengelolaan Pertambangan yang Baik dan Benar, Studi Nusa, Semarang. 